\title{
Aspectos práticos e contemporâneos da linguagem médica voltada para o imaginologista: armadilhas e erros comuns*
}

\author{
Practical and contemporary aspects of medical language in diagnostic imaging: pitfalls and common \\ mistakes
}

Carlos Frederico Arend $^{1}$

Resumo 0 intuito deste artigo é estimular o uso da língua culta pelos médicos que atuam na área de diagnóstico por imagem. Unitermos: Radiologia; Gramática; Língua portuguesa.

Abstract The purpose of this paper is to encourage the correct use of vocabulary in the field of diagnostic imaging. Keywords: Radiology; Grammar; Portuguese.

Arend CF. Aspectos práticos e contemporâneos da linguagem médica voltada para o imaginologista: armadilhas e erros comuns. Radiol Bras. 2013 Mar/Abr;46(2):106-109.

\section{CONSIDERAÇÕES INICIAIS}

As subversões na ortografia e semântica da língua portuguesa são um fenômeno contemporâneo também presente na redação de trabalhos científicos e relatórios de exames médicos. $\mathrm{O}$ intuito deste artigo é resgatar e difundir o uso da língua culta na comunicação entre médicos que atuam na área de diagnóstico por imagem.

\section{ACORDO ORTOGRÁFICO DA LÍNGUA PORTUGUESA}

A língua portuguesa é, como língua nativa, a sétima mais falada no mundo (Tabela 1). Sua origem se deu na parte ocidental da Península Ibérica, a partir do latim vulgar falado pelos soldados romanos, que conquistaram a região em 30 a.C. Nos séculos XV e XVI, a língua se espalhou pelo mundo na medida em que Portugal criava seu império colonial e comercial. Atualmente, é adotada como idioma oficial no Brasil, Portugal, Angola, Moçambique, Guiné Equatorial, Guiné-Bissau, Macau, São Tomé e Príncipe, Timor-Leste e Cabo Verde, contém cerca de 381 mil verbetes ${ }^{(\mathbf{1})}$

\footnotetext{
* Trabalho realizado na Radimagem Diagnóstico por Imagem, Porto Alegre, RS, Brasil.

1. Médico Radiologista da Radimagem Diagnóstico por Imagem, Porto Alegre, RS, Brasil.

Endereço para correspondência: Dr. Carlos Frederico Arend. Avenida Cristóvão Colombo, 1691, Floresta. Porto Alegre, RS, Brasil, 90560-001. E-mail: carlos arend@hotmail.com.

Recebido para publicação em 18/6/2012. Aceito, após revisão, em 5/11/2012.
}

Tabela 1 As dez línguas nativas mais faladas no mundo, em ordem decrescente ${ }^{(2)}$.
1) Chinês
2) Espanhol
3) Inglês
4) Árabe
5) Hindi
6) Bengali
7) Português
8) Russo
9) Japonês
10) Alemão

e abrange uma população superior a 250 milhões de pessoas. Várias foram as tentativas de padronização do idioma entre os países lusófonos ao longo dos séculos. A mais recente, designada Acordo Ortográfico da Língua Portuguesa, é uma proposta para padronização na grafia, que não contempla a língua falada. O acordo também não elimina todas as diferenças ortográficas entre os países signatários, mantidas em aproximadamente $2 \%$ do vocabulário, mas é um importante passo rumo à pretendida unificação. Como elemento motivador para o acordo é citado o caso do espanhol, a segunda língua nativa mais falada no mundo, que apresenta diferenças na pronúncia e no vocabulário entre a Espanha e a América Hispânica, mas está sujeito a uma só forma de escrita, regulamentada pela Asociación de Academias de la Lengua Española. Por outro lado, a ortografia da língua inglesa, a terceira língua nativa mais falada no mundo, apresenta inúmeras variantes nos países anglófonos, sem qualquer regulação específica.

Segundo o Ministério da Cultura, cerca de $0,5 \%$ do nosso vocabulário será afetado pelas mudanças propostas no Acordo Ortográfico da Língua Portuguesa. Em 29 de setembro de 2008 foi assinado o decreto que estabelece o cronograma para sua implementação no Brasil, durante sessão solene na Academia Brasileira de Letras, definindo um período de transição de quatro anos, vigente até 31 de dezembro de 2012, no qual a norma atual e a prevista pelo acordo serão usadas e aceitas como corretas. Está longe de nosso objetivo realizar uma minuciosa descrição das mudanças previstas, que estão esmiuçadas em literatura específica. Nossa finalidade é menos ambiciosa e consiste em destacar algumas das modificações de aplicação prática mais imediata na rotina da imaginologia.

\section{Hífen}

O uso do hífen é o item mais complexo e controverso do acordo e somente foi esclarecido com a publicação da quinta edição do Vocabulário Ortográfico da Língua Portuguesa, que é o documento oficial da Academia Brasileira de Letras ${ }^{(\mathbf{1})}$.

Nas formações com prefixos (como, por exemplo: contra-, extra-, hiper-, infra-, intra-, sub-, supra-, etc.) e em formações por recomposição, isto é, com elementos não autônomos ou falsos prefixos, de origem grega e latina (tais como: macro-, micro-, 
multi-, pseudo-, etc.), se emprega o hífen quando:

a) o prefixo termina com a mesma vogal que se inicia o segundo elemento: intraauricular;

b) os prefixos tônicos acentuados graficamente pré- e pós- se unem a um segundo elemento que tem vida à parte: pré-tibial, pós-operatório.

Não se emprega, pois, o hífen em palavras como supraespinal, infraespinal, subescapular, extramanguito, hiperfluxo, contralateral, pseudoartrose, multipenado e musculotendinosa.

\section{Trema}

O Acordo Ortográfico da Língua Portuguesa preconiza a completa eliminação da diérese, conhecida como trema, exceto para palavras derivadas de nomes próprios estrangeiros com trema, como Müller e mülleriano.

\section{Alfabeto}

Passa a ter 26 elementos, ao incorporar as letras $k, w$ e $y$.

\section{Acentuação}

O acento diferencial é usado em algumas palavras homógrafas para evitar ambiguidade. Ele deixa de existir para diferenciar pólo (substantivo) de polo (combinação de por e lo), como no exemplo abaixo.

- Pseudoartrose no polo inferior do escafoide. (uso correto)

Permanecem os acentos que diferenciam o singular do plural do verbo ter e seus derivados (manter, deter, reter, conter), como nos exemplos abaixo.

- O tendão supraespinal mantém aspecto usual. (uso correto)

- Os tendões do manguito rotador mantêm aspecto habitual. (uso correto)

As regras de utilização da crase não sofreram modificação.

\section{MINIDICIONÁRIO MÉDICO DA LÍNGUA PORTUGUESA}

A língua é dinâmica e vive em permanente renovação, aposentando algumas palavras e criando neologismos para outras. No entanto, a constante renovação do vernáculo deve idealmente obedecer às regras de gramática e estrutura da língua culta. A seguir serão comentadas algumas palavras usualmente empregadas no vocabulário médico.

\section{A nível de (ou ao nível de)}

A utilização da locução a nível de é habitualmente condenada por estudiosos, que a consideram modismo, introduzido originalmente na linguagem jornalística. Ao contrário, a locução ao nível de é averbada em dicionários consagrados, com o sentido de no mesmo plano ${ }^{(\mathbf{3 , 4})}$. Note que o significado correto prevê a comparação entre duas estruturas, como no exemplo a seguir.

- A tenossinovite do primeiro compartimento extensor do carpo usualmente se dá ao nível do processo estilóide do rádio. (uso correto)

Entretanto, a locução ao nível de vem sendo equivocadamente utilizada para designar o local de uma estrutura anatômica, como no exemplo a seguir.

- Ruptura de espessura parcial ao nível da zona crítica do supraespinal. (uso incorreto)

Esta frase poderia ser substituída pela abaixo, de maior correção linguística.

- Ruptura de espessura parcial da zona crítica do supraespinal. (uso correto)

\section{Acurácia (ou precisão)}

Do ponto de vista médico, precisão e acurácia têm significados distintos. Precisão é o grau de semelhança entre os valores de uma variável medida repetidamente, enquanto acurácia é o grau de semelhança entre a variável e o valor real. Assim, a variabilidade interpessoal da ultrassonografia mede a precisão do exame, enquanto sua comparação com um padrão-ouro mede a acurácia. $\mathrm{O}$ exame pode ser preciso, mas não acurado.

\section{Através de}

A expressão através de é averbada em vários dicionários, dando idéia de deslocamento, no espaço ou no tempo, seja concretamente ou na forma de metáfora. Assim, pode ser utilizada de várias formas na linguagem médica, como no exemplo abaixo.

- Células inflamatórias circulantes migram para o espaço intersticial através das paredes capilares. (uso correto)

$\mathrm{O}$ mesmo não se pode dizer da frase a seguir.
- O hiperfluxo é demonstrável através da avaliação com o recurso Doppler. (uso incorreto)

Esta frase poderia ser substituída pela abaixo, de maior correção linguística.

- O hiperfluxo é demonstrável por meio da avaliação com recurso Doppler. (uso correto)

\section{Cãibra (ou cãimbra)}

A consulta aos principais léxicos da língua portuguesa mostra que três registram cãibra $^{(5-7)}$, um registra câimbra ${ }^{(8)}$, um registra igualmente as duas formas ${ }^{(9)}$ e cinco registram cãimbra como variante de cãibra ${ }^{(4}$ 10-13). Desta forma, as duas grafias parecem adequadas.

\section{Cirurgia (ou operação)}

De acordo com os léxicos, cirurgia é uma área do conhecimento médico que se dedica ao tratamento de doenças por meio de operações. Entretanto, em anos recentes, os termos cirurgia e operação vêm sendo utilizados informalmente como sinônimos, não apenas na língua portuguesa, mas também em inglês, o que motivou a publicação de um editorial em renomada revista internacional, criticando o neologismo $^{(\mathbf{1 4})}$. A continuar o uso de cirurgia como sinônimo de operação, é de se prever o aparecimento de um novo verbo cirurgiar $^{(\mathbf{1 5})}$. O exemplo abaixo é um dos clássicos da medicina.

- Indicação do exame: avaliação pós-cirúrgica. (uso incorreto)

Esta frase poderia ser substituída pela abaixo, de maior correção linguística.

- Indicação do exame: avaliação pós-operatória. (uso correto)

\section{Consistente (ou compatível)}

Em língua portuguesa, consistente significa sólido, rijo, espesso, dentre outras acepções. Em inglês, consistent significa compatível, uma definição não encontrada em léxicos da língua portuguesa. Este falso cognato é um típico exemplo do que se convencionou denominar portuglês. O exemplo abaixo é também considerado um clássico.

- Estes achados são consistentes com tenossinovite. (uso incorreto)

Em boa linguagem vernácula, a frase a seguir é mais apropriada. 
- Estes achados são compatíveis com tenossinovite. (uso correto)

\section{Importante}

De acordo com dicionários da língua portuguesa, importante significa algo que importa, essencial. Note que o vocábulo não tem relação com intensidade, como pretendido no exemplo abaixo.

- Importante osteartrose acromioclavicular. (uso incorreto)

Esta frase poderia ser substituída pela abaixo, mais adequada.

- Intensa osteartrose acromioclavicular. (uso correto)

\section{Incipiente (ou insipiente)}

Incipiente e insipiente são parônimos, ou seja, palavras que apresentam pronúncia semelhante e significado diferente. Enquanto incipiente designa estágio inicial, insipiente é considerado um sinônimo para ignorante, néscio. Abaixo seguem exemplos de utilização dos termos.

- Estes achados são comumente observados em portadores de artrite reumatoide incipiente. (uso correto)

- O uso de insipiente com significado de incipiente denota insipiência. (uso correto)

\section{Intravenoso (ou endovenoso)}

O prefixo endo- é grego e, assim, combina naturalmente com outro radical grego, no caso, -flebos, formando endoflébico. $\mathrm{O}$ prefixo intra- é latim e combina com o radical de mesma origem -vena, compondo intravenoso. O hibridismo, termo que designa um vocábulo composto por elementos oriundos de línguas diferentes, usualmente grego e latim, é comumente condenado por puristas. Neste caso específico, endovenoso está averbado em renomados léxicos, consagrado pelo uso, com remissão para intravenoso, o que denota preferência de uso para este último.

\section{Intumescer (ou entumescer ou entumecer)}

O prefixo latino in- deu origem em português aos prefixos in- e en-. Nos léxicos são registrados intumescer, entumescer e entumecer. O Vocabulário Ortográfico da Academia Brasileira de Letras averba as três formas, ainda que intumescer seja a que mais se aproxima do vocábulo latino.

\section{Ipsilateral (ou ipsolateral)}

$\mathrm{Na}$ declinação do pronome latino ipse, ipso corresponde ao ablativo do singular ${ }^{(\mathbf{1 6})}$. Em latim, o ablativo expressa o adjunto adverbial, enquanto o dativo é empregado como objeto indireto ${ }^{(17)}$. Assim, do ponto de vista estritamente acadêmico, a grafia correta é ipsolateral. O dicionário Aurélio já registra ipsilateral ${ }^{(4)}$, consagrado pelo uso, ao contrário do Vocabulário Ortográfico da Academia Brasileira de Letras, que só averba ipsolateral ${ }^{(\mathbf{1})}$.

\section{Laudar}

O verbo laudar e seu particípio laudado não são registrados no Vocabulário Ortográfico da Academia Brasileira de Letras, nem em dicionários como o Aurélio, o Michaelis e o Houaiss. Laudo, por sua vez, é averbado com o significado de peça escrita que registra as conclusões de perícia, esta última considerada um exame de caráter técnico ou especializado. Assim, embora o substantivo laudo tenha ampla aplicabilidade na imaginologia, o uso do verbo laudar e suas variações é condenável pela linguagem vernácula, como orienta a frase abaixo.

- Ainda preciso laudar oito exames antes de ir para casa descansar. (uso incorreto). Se este trabalho ainda precisa ser realizado antes do merecido descanso, informe com mais correção utilizando o exemplo abaixo.

- Ainda preciso redigir o relatório de oito exames antes de ir para casa descansar. (uso correto)

\section{Patologia (ou doença)}

De acordo com dicionários da língua portuguesa, patologia é uma área da medicina que descreve as alterações causadas pelas doenças. No entanto, em anos recentes, os termos patologia e doença vêm sendo utilizados como sinônimos, não apenas em português, mas também em inglês e espanhol, gerando um neologismo ainda não averbado em nenhum léxico de nosso idioma. Em linguagem vernácula, informar que o paciente tem uma patologia seria o equivalente a dizer que o paciente tem uma cardiologia em lugar de uma cardiopatia ${ }^{(\mathbf{1 8})}$. O exemplo abaixo é um clássico.

- A tendinose é uma patologia degenerativa. (uso incorreto)
Esta frase poderia ser substituída pela abaixo, mais correta.

- A tendinose é uma doença degenerativa. (uso correto)

\section{Pré-requisito (ou requisito)}

Requisito é definido nos léxicos como uma condição necessária para se alcançar certo objetivo. Pré-requisito é, portanto, uma redundância. Requisito é suficiente.

\section{Ruptura (ou rotura ou rutura)}

Em latim clássico havia o substantivo ruptura, que se transformou em ruttura na passagem para o latim vulgar, posteriormente reduzido para rutura em português $^{(19)}$. Com o passar dos anos, a vogal $u$ se transformou em $o$ e o vocábulo evoluiu para rotura ${ }^{(\mathbf{2 0})}$. O termo ruptura, em português, é mais recente, criando uma duplicidade também presente em espanhol. A forma rutura é pouco usada atualmente e já não aparece em dicionários mais recentes, ao contrário de rotura e ruptura, ambas averbadas no Vocabulário Ortográfico da Academia Brasileira de Letras ${ }^{(\mathbf{1})}$.

\section{Topografia}

Em língua portuguesa, topografia designa a ciência que realiza a descrição detalhada de um local, incluindo aspectos morfológicos e altimétricos, que permitem a execução de projetos e obras por engenheiros ou arquitetos. $\mathrm{O}$ exemplo abaixo ilustra seu uso incorreto na área médica.

- Dor na topografia da cabeça longa do bíceps. (uso incorreto)

O exemplo acima pode ser substituído pelo abaixo, mais adequado.

- Dor na região da cabeça longa do bíceps. (uso correto)

\section{Visualizar (ou visibilizar)}

Visibilizar provém do adjetivo latino visibilis, que significa visível em português. Visualizar deriva de adjetivo latino visualis, que significa visual em português. Visível é tudo aquilo que se pode ver, ao passo que visual se refere ao sentido da visão. A segunda edição do dicionário Aurélio ainda mantinha a distinção entre os dois verbos ${ }^{(21)}$, denotando a visualizar o sentido de conceber uma imagem visual de algo que não se tem ante os olhos no momento. A mesma obra foi modificada em sua terceira edição, 
que tornou o significado de visualizar mais abrangente, correspondente ao ato de tornar visível durante manobra ou procedimento $^{(\mathbf{4})}$. Assim, no contexto da imaginologia, as duas grafias parecem adequadas.

\section{CURIOSIDADE: A MAIOR PALAVRA DA LÍNGUA PORTUGUESA}

Existem poucos assuntos tão controversos como a designação da maior palavra da língua portuguesa. O maior verbete listado no Vocabulário Ortográfico da Língua Portuguesa é oftalmotorrinolaringologista, atualmente obsoleto, com 28 letras $^{(\mathbf{1})}$. O Guinness World Records considera inconstitucionalissimamente, com 27 letras, que indica o mais alto grau de inconstitucionalidade $^{(22)}$. No Dicionário Houaiss, a maior palavra é um termo técnico, pneumoultramicroscopicossilicovulcanoconiótico, com 46 letras, que denota o estado de quem é portador de uma enfermidade pulmonar causada pela aspiração de cinzas vulcânicas ${ }^{(\mathbf{1 1})}$. No entanto, termos técnicos e plurais usualmente não são considerados na disputa. Se nomes técnicos fossem admitidos, a palavra mais longa do mundo seria o nome cientí- fico da conectina, a maior proteína conhecida, responsável pela elasticidade muscular, que contém, em nossa livre tradução, cerca de 196.099(!) letras (metioniltreoniltreonilglutaminilarginiltirosil...) $)^{(23)}$.

\section{REFERÊNCIAS}

1. Academia Brasileira de Letras. Vocabulário ortográfico da língua portuguesa. São Paulo, SP: Editora Global; 2009.

2. Lewis MP. Ethnologue: languages of the world. Dallas, TX: SIL International; 2009.

3. Michaelis - Moderno dicionário da língua portuguesa. São Paulo, SP: Melhoramentos; 1998.

4. Ferreira $\mathrm{ABH}$. Novo dicionário da língua portuguesa. Rio de Janeiro, RJ: Editora Nova Fronteira; 1999.

5. Silva AM. Grande dicionário da língua portuguesa. Lisboa, Portugal: Editorial Confluência; 1949-1959.

6. Aulete FJC. Dicionário contemporâneo da língua portuguesa. Lisboa, Portugal: Imprensa Nacional; 1881.

7. Seguier J. Dicionário prático ilustrado. Porto, Portugal: Lello \& Irmão Editores; 1981.

8. Rey L. Dicionário de termos técnicos de medicina e saúde. Rio de Janeiro, RJ: Guanabara Koogan; 1999.

9. Heckler E, Back S, Massing ER. Dicionário morfológico da língua portuguesa. São Leopoldo, RS: Editora Unisinos; 1984.

10. Grande dicionário brasileiro Melhoramentos. São Paulo, SP: Melhoramentos; 1975.
11. Houaiss A, Villar MS. Dicionário Houaiss da língua portuguesa. Rio de Janeiro, RJ: Editora Objetiva; 2001.

12. Figueiredo C. Dicionário da língua portuguesa. Lisboa, Portugal: Livraria Bertrand; 1949.

13. Aulete FJC, Garcia H. Dicionário contemporâneo da língua portuguesa. Rio de Janeiro, RJ: Editora Delta; 1980.

14. Marshaw AI, Sarr MG. Does the patient undergo a surgery or an operation? Surgery. 2006;139:173.

15. Rezende JM. Linguagem médica. São Paulo, SP Editora Byk; 1992.

16. Faria E. Gramática superior da língua latina. Rio de Janeiro, RJ: Livraria Acadêmica; 1958.

17. Almeida NM. Gramática latina. São Paulo, SP: Editora Saraiva; 1980.

18. Becker I. Nomenclatura biomédica no idioma português do Brasil. São Paulo, SP: Livraria Nobel; 1968.

19. Williams EB. Do latim ao português. Rio de Janeiro, RJ: Instituto Nacional do Livro/MEC; 1961.

20. Machado JP. Dicionário onomástico etimológico da língua portuguesa. Lisboa, Portugal: Ed. Confluência; s/d.

21. Ferreira $\mathrm{ABH}$. Novo dicionário da língua portuguesa. Rio de Janeiro, RJ: Editora Nova Fronteira; 1986

22. Guinness World Records 2010 - Livro dos recordes. Rio de Janeiro, RJ: Editora Ediouro; 2010.

23. Arend CF. MASTER ultrassonografia musculoesquelética. $2^{a}$ ed. Rio de Janeiro, RJ: Editora Revinter; 2012. 